\title{
Estimation of wind speed profile using adaptive neuro-fuzzy inference system (ANFIS)
}

\author{
M. Mohandes ${ }^{\mathrm{a}, *}$, S. Rehman ${ }^{\mathrm{b}, \mathrm{c}}$, S.M. Rahman ${ }^{\mathrm{d}}$ \\ ${ }^{a}$ Electrical Engineering Department, King Fahd University of Petroleum E Minerals, KFUPM 1885, Dhahran 31261, Saudi Arabia \\ ${ }^{b}$ Center for Engineering Research, King Fahd University of Petroleum E Minerals, KFUPM 767, Dhahran 31261, Saudi Arabia \\ ${ }^{\mathrm{c}}$ Mechanical and Aeronautical Engineering Department, University of Pretoria, Pretoria, South Africa \\ ${ }^{\mathrm{d}}$ Center for Environment and Water, King Fahd University of Petroleum E Minerals, Dhahran 31261, Saudi Arabia
}

\section{A R T I C L E I N F O}

\section{Article history:}

Received 20 February 2011

Accepted 4 April 2011

Available online $\mathrm{xxxx}$

\section{Keywords:}

ANFIS

Fuzzy inference system

Artificial neural networks

Wind profile

Wind speed

\begin{abstract}
A B S T R A C T
Wind energy has become a major competitor of traditional fossil fuel energy, particularly with the successful operation of multi-megawatt sized wind turbines. However, wind with reasonable speed is not adequately sustainable everywhere to build an economical wind farm. The potential site has to be thoroughly investigated at least with respect to wind speed profile and air density. Wind speed increases with height, thus an increase of the height of turbine rotor leads to more generated power. Therefore, it is imperative to have a precise knowledge of wind speed profiles in order to assess the potential for a wind farm site. This paper proposes a clustering algorithm based neuro-fuzzy method to find wind speed profile up to height of $100 \mathrm{~m}$ based on knowledge of wind speed at heights 10, 20, 30, $40 \mathrm{~m}$. The model estimated wind speed at $40 \mathrm{~m}$ based on measured data at 10,20 , and $30 \mathrm{~m}$ has $3 \%$ mean absolute percent error when compared with measured wind speed at height $40 \mathrm{~m}$. This close agreement between estimated and measured wind speed at $40 \mathrm{~m}$ indicates the viability of the proposed method. The comparison with the $1 / 7$ th law and experimental wind shear method further proofs the suitability of the proposed method for generating wind speed profile based on knowledge of wind speed at lower heights.
\end{abstract}

(c) 2011 Elsevier Ltd. All rights reserved.

\section{Introduction}

Wind, as an energy resource has gained significant focus around the world. The power of wind is generally regarded as one of the very important sources of renewable, inexhaustible, and clean energy. Wind energy has become a competitor of traditional fossil fuel power plants with the successful operation of multi-megawatt sized wind turbines. However, this absolutely free energy source is not adequately available everywhere to build an economical wind farm. The potential site has to be thoroughly investigated at least with respect to wind speed profile and air density. The increased height of turbine rotor leads to more generated power because wind speed increases with height. In order to assess the potential of a wind farm site, it is imperative to have precise knowledge of wind speed profiles. This study attempts to estimate the wind profile using neuro-fuzzy method.

Renewable energy has been considered as one of the strong contenders to improve plight of 2 billion people who are not having access to modern forms of energy [1]. At the same time, at least

\footnotetext{
* Corresponding author.

E-mail addresses: mohandes@kfupm.edu.sa (M. Mohandes), srehman@kfupm. edu.sa (S. Rehman).
}

another half a billion people living in the regions where the population is growing most rapidly, have limited or unreliable access to energy [2]. An accurate wind resource assessment plays a vital role for harnessing the power of the wind [3]. Wind assessment techniques are used to create wind maps on a local scale and micrositing of wind turbines, estimate vertical wind speed variations and long-term wind resource at a given site [4]. These techniques made it possible to conduct wind assessment studies all over the world like Qatar [5] and Nigeria [6], a few sites in Jordan [7] and Kuwait [8], a wind atlas of Quebec, Canada [9], offshore California [10], the Red Sea coast and in Egypt [11].

Potts et al. [12] used GIS based software (WindMap) to perform the wind resources assessment of Western and Central Massachusetts. Brower [13] developed maps for monthly and annual mean wind speeds in Iowa using wind speed data from 21 locations, which would be beneficial for interested wind farms developers to obtain reasonably accurate estimates of potential wind energy production in Iowa. Raichle and Carson [14] reported that ridges in the Southern Appalachian Mountain region are suitable for utility-scale wind development. Muzathik et al. [15] studied the daily, monthly and annual wind speed along with their prevailing direction at a site in Terengganu, Malaysia, and concluded that small ( $\mathrm{kW}$ range) wind machines could be used to provide power during the northeast monsoon season. 
In Saudi Arabia, a wind atlas was developed which presented the monthly mean wind speed contours and frequency distribution for all the months of the year [16]. Rehman and Halawani [17] presented the statistical characteristics of wind speed and its diurnal variation for several sites in Saudi Arabia. Rehman et al. [18] adopted net present value approach to compute the cost of energy generation at 20 locations. Rehman and Al-Abbadi [19] presented the calculated values of wind shear coefficients (WSE) using measured values of wind speed at 20,30 , and $40 \mathrm{~m}$ above ground level, for Dhahran. Al-Abbadi and Rehman [20] presented the wind speed characteristics including wind statistics, local values of WSE, Weibull distribution parameters, turbulence intensity (TI), and wind energy yield using wind speed measurements made at different heights for Gassim city.

Due to increasing emphasis on wind power utilization and accurate wind power assessment and better hands on information in future time domain, long-term wind speed prediction is very important for siting and sizing of wind power applications $[21,22]$. On the other hand, the short-term forecasting of wind speed is important for improving the efficiency of a wind power generation systems [23] as well as for the integration of wind energy into the power system [24]. Furthermore, the forecasts in the range of days are related to the maintenance and resources planning of the wind power plants [25]. There are several methods in the literature used for the prediction of wind speed for different time durations and include different physical models, statistical methods, hybrid physical-statistical methods, artificial intelligence

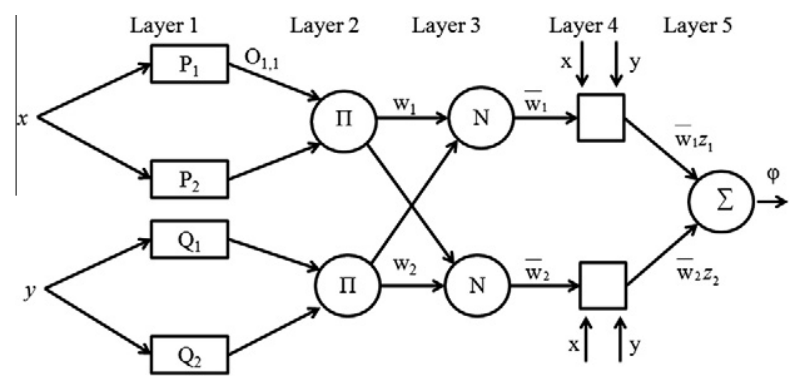

Fig. 1. The architecture of ANFIS. and neurofuzzy, and other modern methods [26,27]. Recently, Li and Shi [28] presented a comparative study on the application of 3 types of neural networks (adaptive linear element, back propagation, and radial basis function) for the prediction of wind speed 1-h ahead. Their results showed that no single neural network model outperforms the others universally in terms of all evaluation metrics.

In this paper a neuro-fuzzy model is used to estimate wind speed at high altitudes based on measurements at lower heights in Juaymah city of Saudi Arabia. The neuro-fuzzy model exploits the capability of both neural network and fuzzy logic systems. Fuzzy logic theory allows better representation of a given system behavior using a set of simple rules although it is unable to tackle knowledge stored in the form of numerical data [29]. On the other hand, artificial neural network (ANN) has been shown to be capable of learning virtually any smooth nonlinear function with a high degree of accuracy through a learning process. However, it shows limited capability in handing systems represented by linguistic information. Jang [30] proposed a neuro-fuzzy system known as adaptive neuro-fuzzy inference system (ANFIS). The ANFIS architecture has been successfully used to model nonlinear functions, identify nonlinear components in a control system, and predict a chaotic time series [31]. ANFIS is used in this paper for the estimation of wind speed profile.

Section 2 of this paper discusses briefly the ANFIS system while section 3 describes its application for wind profile estimation. Section 4 describes the obtained results. Section 5 concludes the paper.

\section{ANFIS based methodology}

ANFIS was developed to serve as a basis for constructing fuzzy inference system (FIS), and its architecture is obtained by embedding the fuzzy inference system into a framework of ANN [30]. Fig. 1 shows the architecture of ANFIS model for 2 inputs ( $x$ and $y$ ). The functions of each layer are described below.

\subsection{First layer}

It is called input layer. It maps the crisp inputs using membership functions. The value of membership grade varies between 0

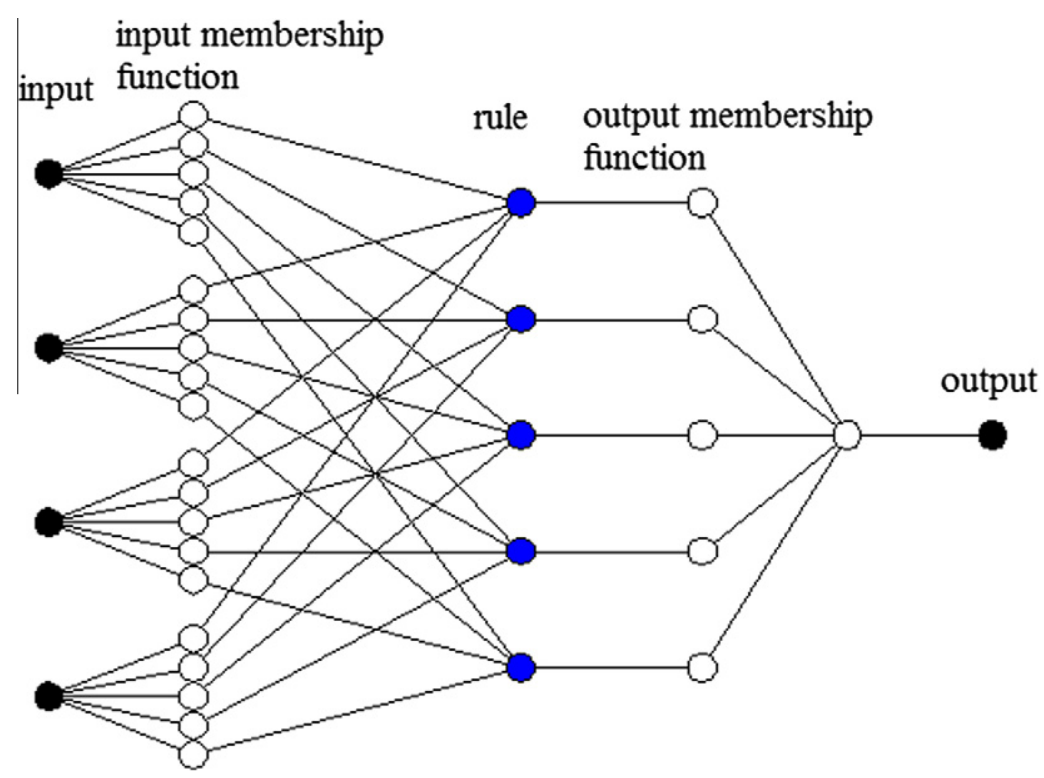

Fig. 2. ANFIS structure of the system of wind profile. 


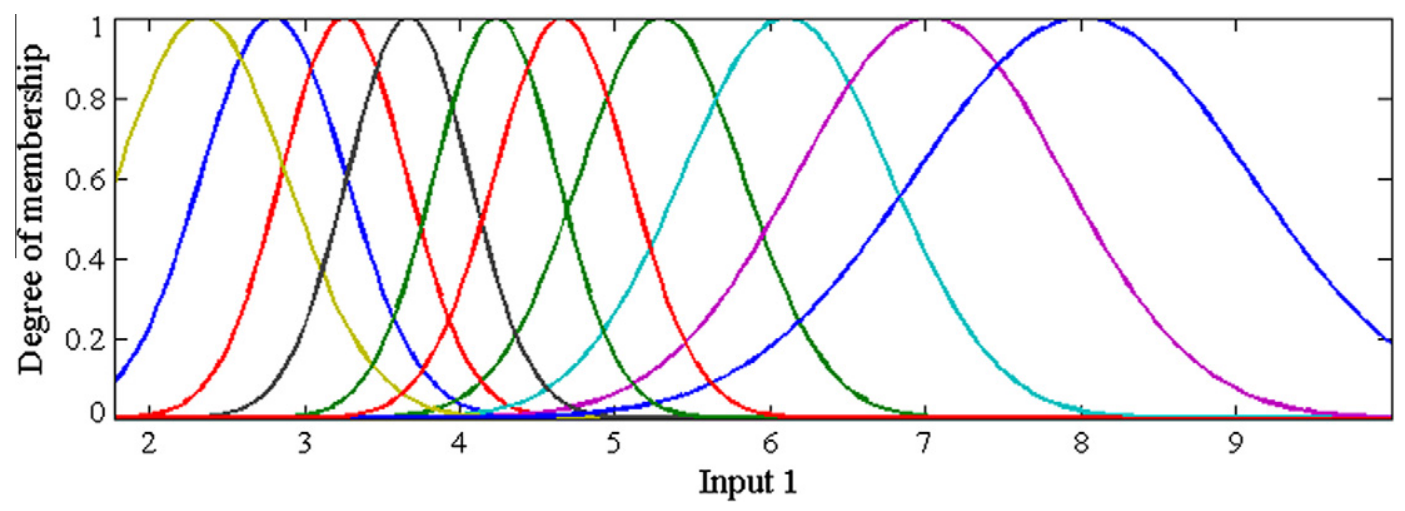

Fig. 3. Final membership functions of the input 1.

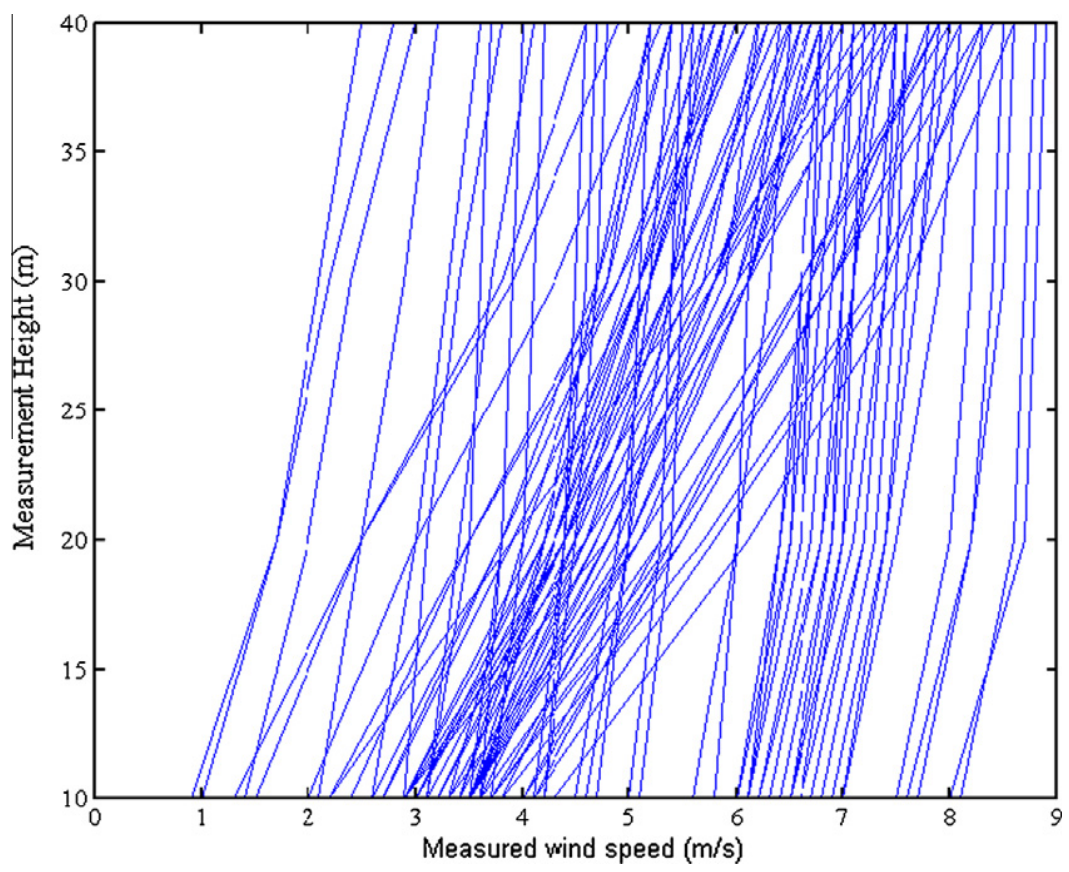

Fig. 4. Samples of $10 \mathrm{~min}$ average of measured WS at heights $10-40 \mathrm{~m}$.

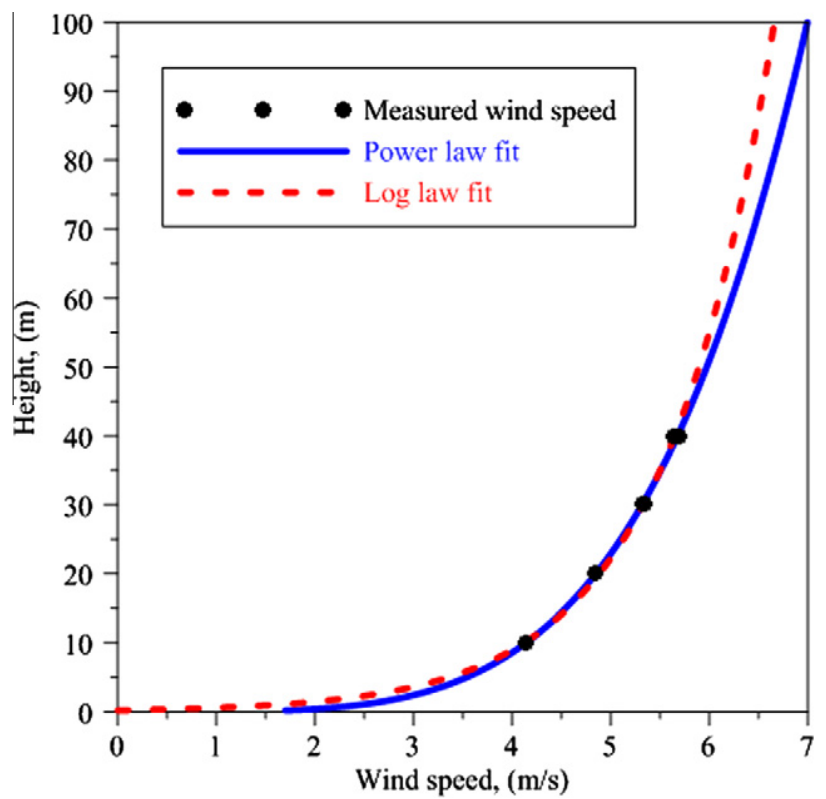

Fig. 5. Estimation of wind shear exponent (WSE) for Juaymah using entire data set. 


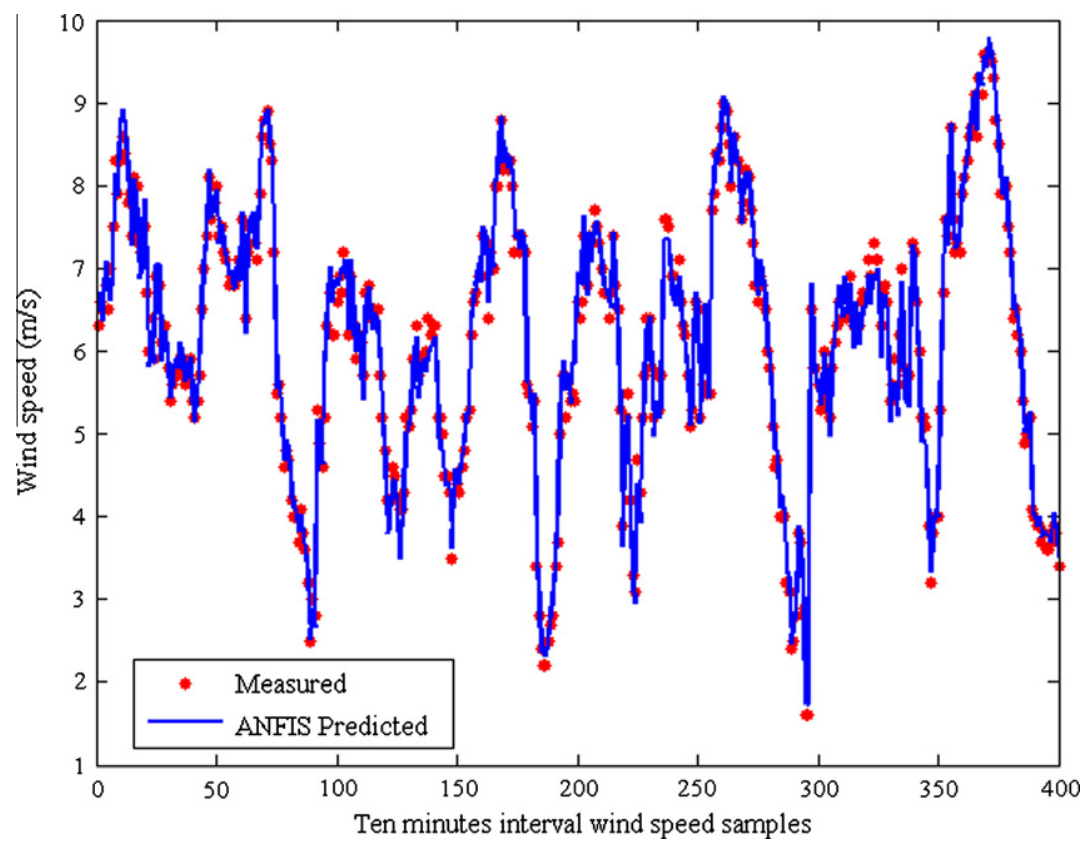

Fig. 6. Comparison of $10 \mathrm{~min}$ average measured and predicted WS at $40 \mathrm{~m}$ AGL.

and 1. Each node of this layer stores the parameters to define a bell-shaped membership function $(\mu)$ as given by:

$$
\begin{aligned}
& O_{1, i}=\mu_{P_{i}}(x) \\
& O_{1, j}=\mu_{Q_{j-2}}(y) \\
& \mu(x)=\exp \left\{-\frac{1}{2}\left(\frac{x-c}{\sigma}\right)^{2}\right\}
\end{aligned}
$$

where $i=1,2$ and $j=3,4 ; x$ and $y$ are the inputs; $P_{i}$ or $Q_{j}$ are the linguistic label; $c$ and $\sigma$ are the mean and standard deviation of the membership function respectively which are also known as premise parameters.

\subsection{Second layer}

Each node of this layer performs connective operation "AND" within the rule antecedent to determine the corresponding firing strength, $w_{k}$. The node function of this layer can be written as follows:

$O_{2, k}=\mu_{P_{k}}(x) * \mu_{Q_{k}}(y)=w_{k} ; \quad$ for $k=1,2$

\subsection{Third layer}

The nodes of this layer perform a normalization process to produce the normalized firing strength:

$O_{3, k}=\frac{w_{k}}{\Sigma w_{k}}=\bar{w}_{k} ; \quad$ for $k=1,2$

\subsection{Fourth layer}

The fourth layer deals with the consequent part of the fuzzy rule. The node of this layer is adaptive with output:

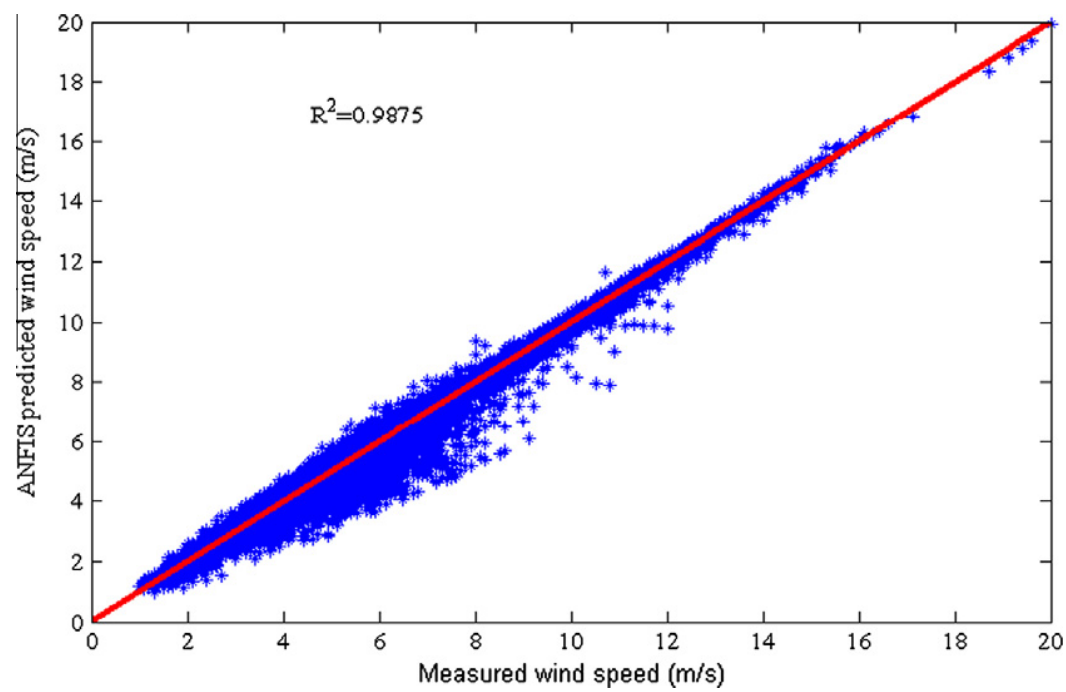

Fig. 7. Scatter diagram of measured and predicted WS values at $40 \mathrm{~m}$ AGL. 


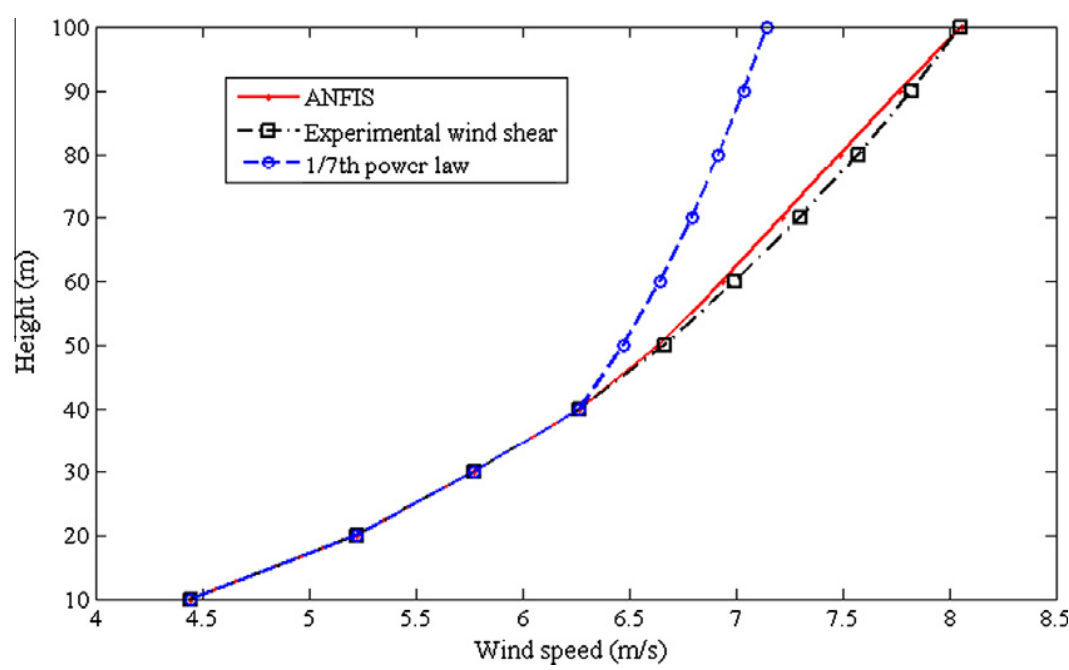

Fig. 8. Performance of ANFIS algorithm on estimating WS values at heights $50-100 \mathrm{~m}$.

$O_{4, k}=\bar{w}_{k} z_{k}$

where $z_{k}=\alpha_{k}+\beta_{k} x+\gamma_{k} y ; \alpha, \beta$, and $\gamma$ are constant parameters and $k=1,2$.

\subsection{Fifth layer}

The final output is the weighted average of all rule outputs. It is computed as:

$O_{5}=\sum_{k=1}^{2} \bar{w}_{k}\left(\alpha_{k}+\beta_{k} x+\gamma_{k} y\right)=\varphi$

where $\varphi$ is model output.

Based on the above discussion on ANFIS architecture, it can be concluded that if the premise parameters are fixed then the output of the whole system is a linear combination of the consequent parameters [32]. Ultimately, the output can be written as the following matrix format for $n$ number of training samples.

$\varphi=\mathrm{AP}$

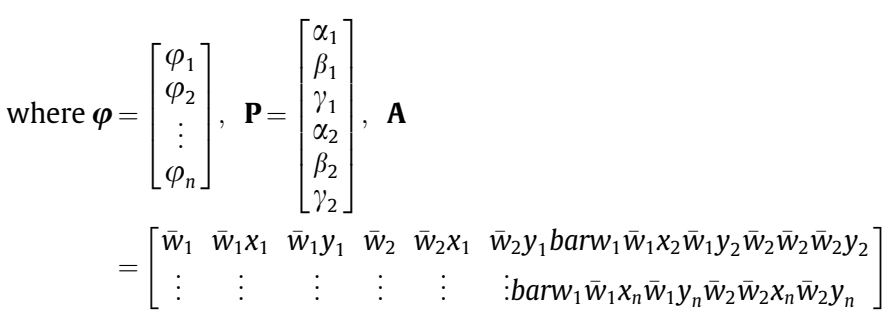

The unknown matrix $\mathbf{P}$ can be estimated by using the least squares method. The hybrid learning algorithm of the ANFIS is a combination of the gradient descent technique and the least squares method for learning the premise and consequent parameters respectively. Now, for a premise parameter $(\delta)$, the overall error $(E)$ can be expressed in terms of $\delta$ :

$\nabla \delta=-\eta \frac{\partial E}{\partial \delta}$

where $\eta=$ learning rate, $E=\sum_{i=1}^{n}\left(T_{i}-\varphi_{i}\right)^{2}, T=$ target and $\varphi=$ model output

All the above computation of the ANFIS model is performed in MATLAB environment. More details about the ANFIS algorithm can be found in [30].
Table 1

Mean percent errors between WS values obtained from the three different approaches.

\begin{tabular}{llll}
\hline $\begin{array}{l}\text { Height } \\
(\mathrm{m})\end{array}$ & $\begin{array}{l}\text { 1/7th power law and } \\
\text { ANFIS }(\%)\end{array}$ & $\begin{array}{l}\text { ANFIS and local } \\
\text { WSE }(\%)\end{array}$ & $\begin{array}{l}\text { 1/7th power law and } \\
\text { local WSE }(\%)\end{array}$ \\
\hline 50 & 2.57 & 0.36 & 2.86 \\
60 & 4.49 & 0.88 & 5.13 \\
70 & 6.29 & 1.16 & 7.02 \\
80 & 8.19 & 1.13 & 8.62 \\
90 & 10.33 & 0.71 & 10.01 \\
100 & 12.76 & 0.10 & 11.23 \\
Average & $\mathbf{7 . 4 4}$ & $\mathbf{0 . 7 2}$ & $\mathbf{7 . 4 8}$ \\
\hline
\end{tabular}

\section{Implementation}

The wind speed profile is estimated using the above mentioned ANFIS based methodology. As the Gaussian membership functions are the most common, they are considered in this paper. Different values of the fuzzy exponent were investigated and the value of 2 was found to a system that performs reasonably well. Moreover, several numbers of membership functions were considered to find optimum number. Based on many experiments, the number of membership functions (MFs) was selected as 10 for all the developed models. The increased number of MFs typically causes increased training time. Fig. 2 illustrates the architecture of one of the proposed ANFIS models with 4 inputs, 1 output and 5 fuzzy rules. The initial value of the step size for training the ANFIS model was fixed at 0.01 .

Based on the above settings, the training of the ANFIS model was performed in MATLAB environment. It was observed that the root mean square errors of the proposed models became steady after 5 epochs of the training data. Typically, the number of epochs is not important in the training process of ANFIS model [33]. As an example, the final membership functions of input 1 (wind speed at $10 \mathrm{~m}$ height) are provided in Fig. 3.

\section{Results and discussion}

Wind fluctuates significantly with time and height as shown in Fig. 4. This makes the estimation of wind speed at higher hub heights a challenging task. Usually, wind speed measurements are made at $10 \mathrm{~m}$ or so above the ground level. The wind profile 


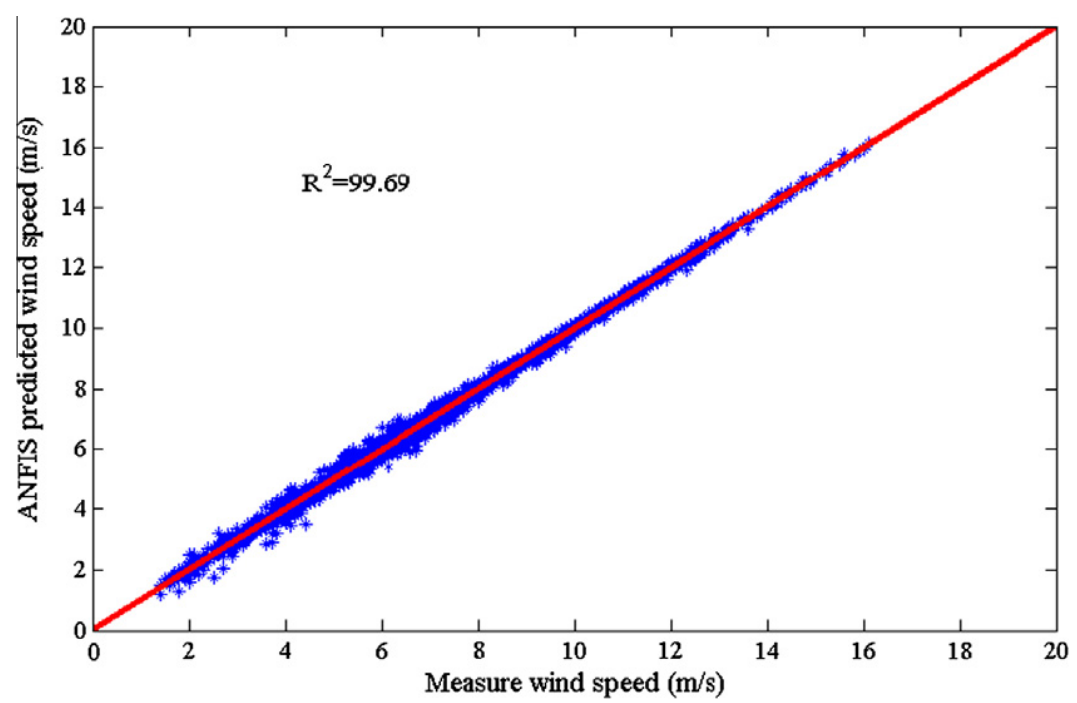

Fig. 9. Measured and predicted WS at $40 \mathrm{~m}$ for July 2006.

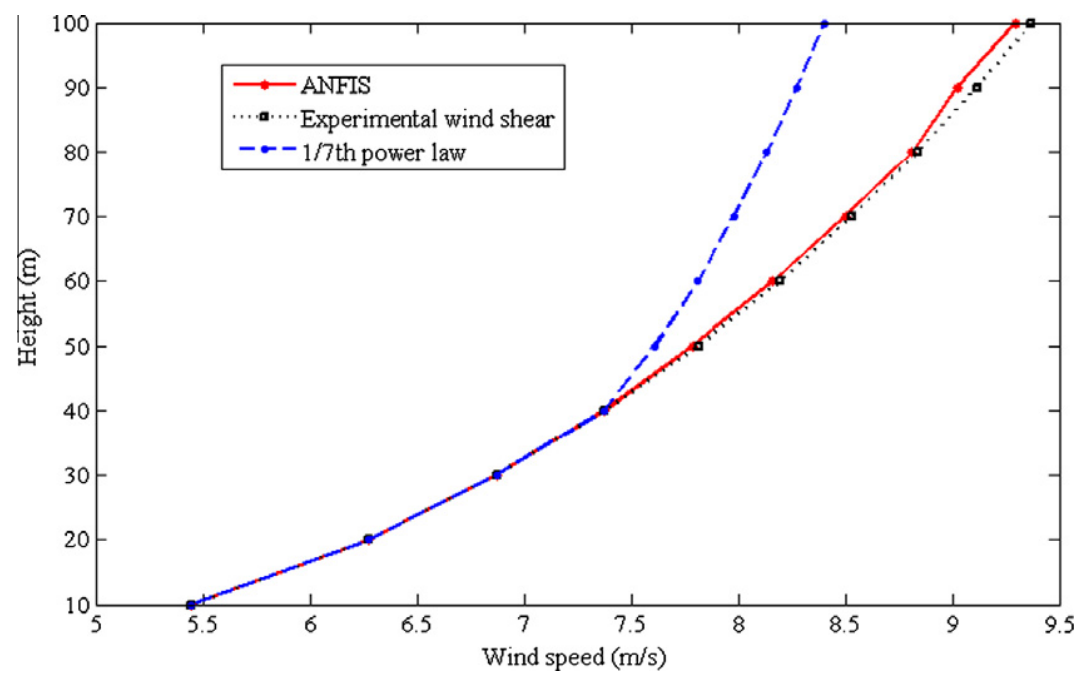

Fig. 10. Performance of ANFIS algorithm on estimating WS values at heights 50-100 m for July 2006 .

at higher heights is needed to assess the wind energy potential. The estimation of wind speed at higher height based on $1 / 7$ th wind power law is a matter of concern and raises questions about its accuracy. The other practice is to install wind masts of 40 to $100 \mathrm{~m}$ tall and make wind measurements at different heights over a certain period of time and then calculate the local wind shear exponent. Finally, this local wind shear exponent should be used to extrapolate the wind speed at hub-height to get accurate estimates. Alternatively, modern machine learning techniques can be used to estimate wind speed using available wind measurements at lower heights.

The present study utilizes wind speed measurements made at 10, 20, 30 and $40 \mathrm{~m}$ Above Ground Level (AGL) at Juaymah, Saudi Arabia for a period of 17 months between July 01, 2006 and November 30, 2007. The wind shear exponent (WSE) calculated using the entire data set was 0.274 and the methodology used for its estimation is shown in Fig. 5. The ANFIS model is trained on the first 3 wind speed values at heights 10,20 and $30 \mathrm{~m}$ to predict wind speed at $40 \mathrm{~m}$. The trained ANFIS model is tested using the wind speed values at heights 20,30 , and $40 \mathrm{~m}$ to predict at $50 \mathrm{~m}$. This process continues with using the newly generated val- ues to predict the values at higher heights until $100 \mathrm{~m}$. Different scenarios based on wind speed measurement records and averaging periods have been used to understand the practical utility of the proposed new method. In first scenario, 10 min averaged wind speed values over the entire data collection period are used. In second scenario, 10 min average wind speed over 1 month period is used. In third case, the daily average values over entire data collection period have been utilized to study the sensitivity of the method over different data sizes and averaging periods.

\subsection{Scenario number one}

In this case a total of 74,661 records were taken initially and a filter was applied to discard the records having wind speed (WS) values less than or equal to the threshold value of the wind speed. Moreover, cases where wind speed at $10 \mathrm{~m}$ is greater than at $20 \mathrm{~m}$ or wind speed at $20 \mathrm{~m}$ was greater than at $30 \mathrm{~m}$ or wind speed at $30 \mathrm{~m}$ was greater than at $40 \mathrm{~m}$ are removed as well. These cases may have resulted from shading effects of main pole on the sensors. After the application of this filter a total of 55,115 valid records were found to be suitable for further analysis. As 


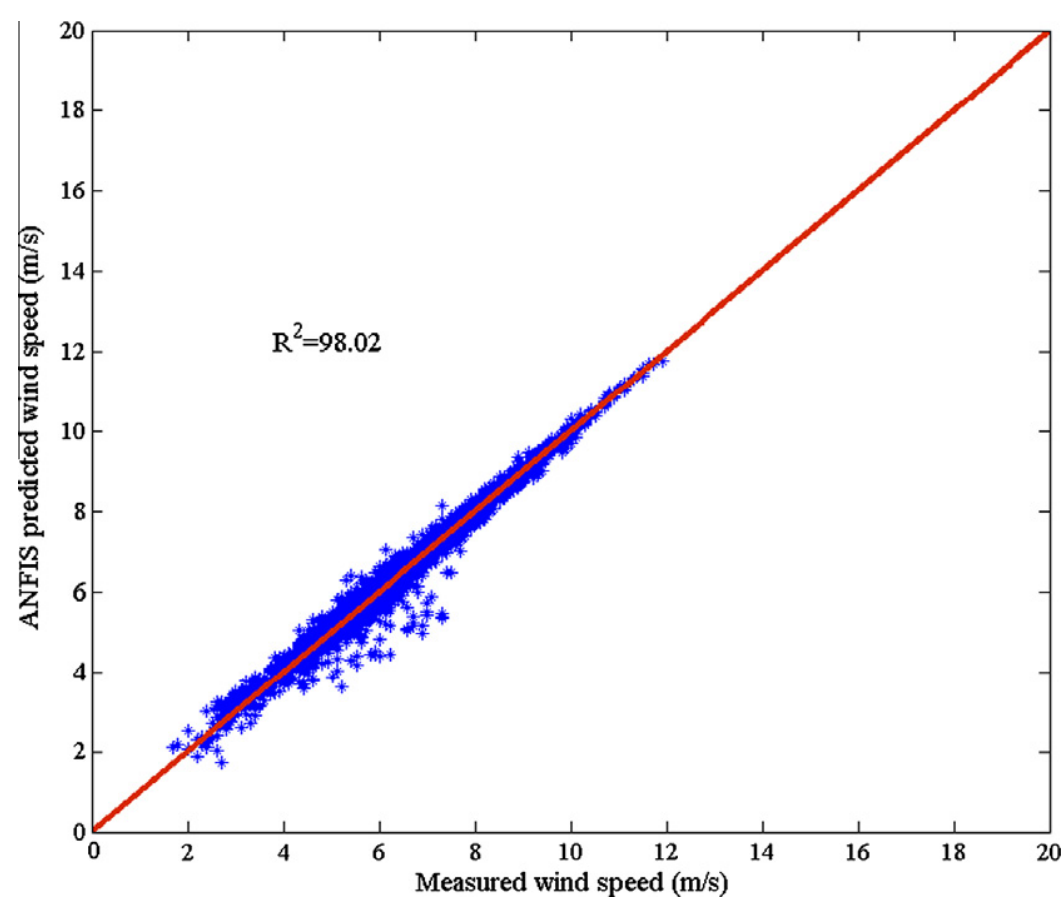

Fig. 11. Measured and predicted WS at $40 \mathrm{~m}$ for January 2007.

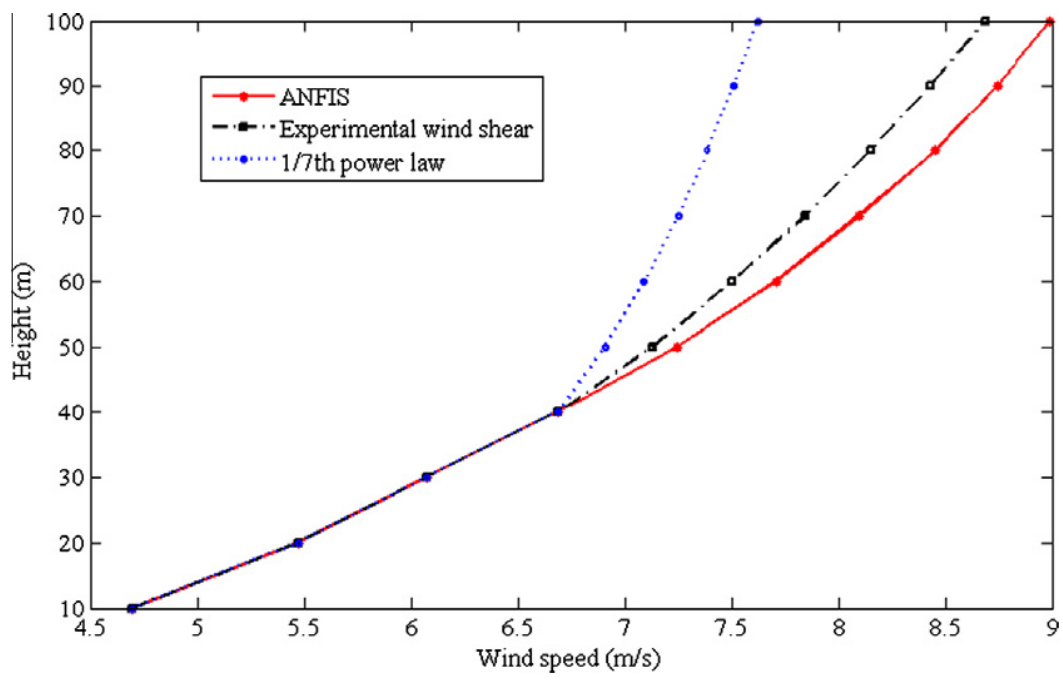

Fig. 12. Performance of ANFIS algorithm on estimating WS values at heights 50-100 m for January 2007.

mentioned earlier, wind speeds at 10,20 , and $30 \mathrm{~m}$ were used to train the ANFIS model and then get WS at $40 \mathrm{~m}$ by using all the valid records. The predicted WS at $40 \mathrm{~m}$ was compared with the measured WS at this height and the mean absolute percent error between the two was 3.03\%. The measured and the predicted WS values over a range of records, for the sake of clarity, are shown in Fig. 6. It is evident from this figure that the measured and predicted WS values at $40 \mathrm{~m}$ are in close agreement. In order to further assess the strength of the ANFIS method, the predicted WS values were plotted against the measured ones, as shown in Fig. 7. The WS values lie around a straight line passing through the origin which simply implies a very close agreement between the two. Furthermore, the $R^{2}$ value was 0.9875 , i.e. almost unity. After testifying the validity of the present method by comparing it with the measured value at $40 \mathrm{~m}$, the WS values were estimated $50-100 \mathrm{~m}$ in $10 \mathrm{~m}$ steps.
The WS values predicted using ANFIS are compared with those extrapolated using local wind shear exponent (WSE $=0.274)$ and the $1 / 7$ th wind power law in Fig. 8 . The ANFIS predicted values were found to be in close agreement with those obtained using local WSE while $1 / 7$ th power law based values were very different than the two above. The percent errors between the $1 / 7$ th power law and ANFIS, ANFIS and local WSE, and 1/7th power law and local WSE based estimations are summarized in Table 1.

\subsection{Scenario number two}

In this case a shorter data set (for the month of July 2006) of 4464 records was initially used and after applying the filters, as explained earlier, a total of 3632 valid records were obtained. The data for July was used to represent typical summer weather in the region. The WS values obtained using ANFIS at $40 \mathrm{~m}$ were in 


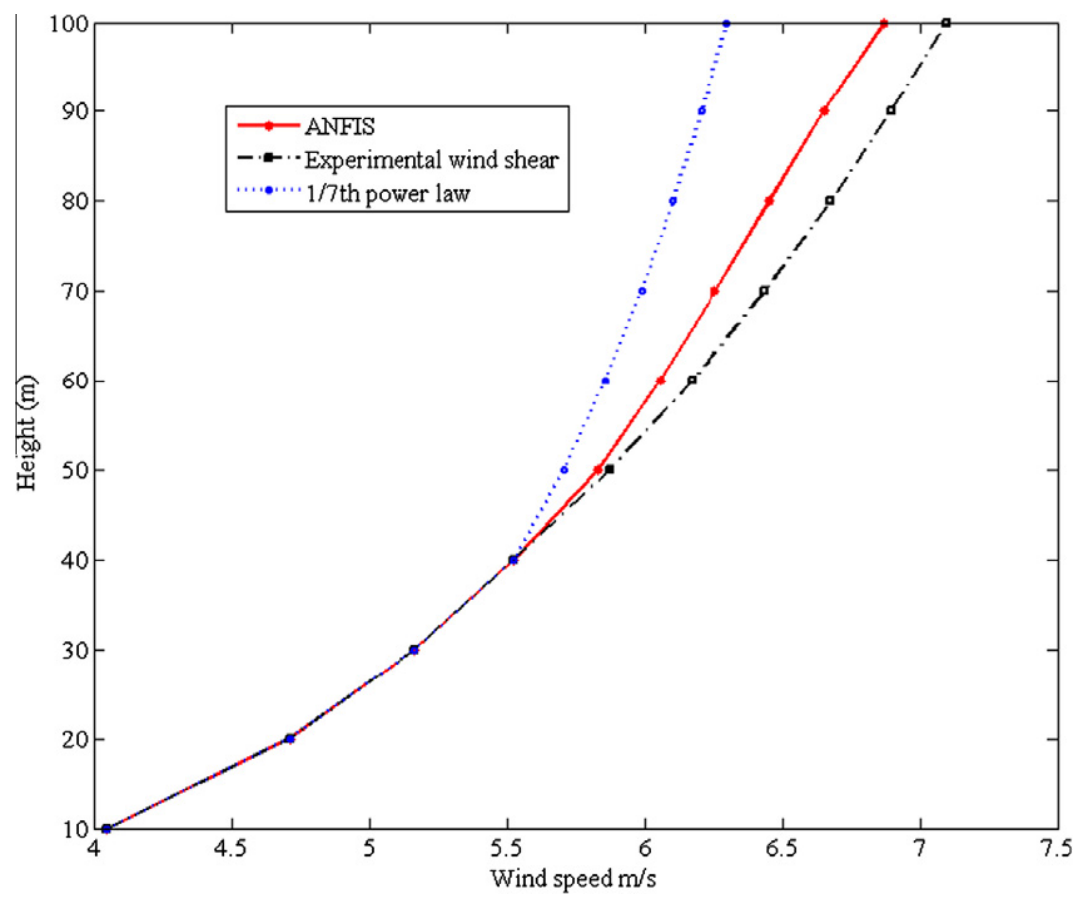

Fig. 13. Performance of ANFIS algorithm on estimating daily average WS values at heights $50-100 \mathrm{~m}$.

close agreement with the measured ones with a MAPE of $1.91 \%$ and $R^{2}$ value of 99.69, as shown in Fig. 9. The vertical variation of WS, extrapolated from 50 to $100 \mathrm{~m}$ heights using 1/7th power law, ANFIS and local WSE is shown in Fig. 10. The ANFIS estimated WS values are in very close to the one obtained using local WSE while the ones obtained using $1 / 7$ th power law are much more deviated from the two.

For further validation, WS data in January was selected as representative winter weather in the region. In this case, the WS values obtained using ANFIS at $40 \mathrm{~m}$ were in close agreement with the measured ones with a MAPE of $1.21 \%$ and $R^{2}$ value of 98.02 , as can be seen from Fig. 11. The vertical variation of WS, extrapolated from 50 to $100 \mathrm{~m}$ heights using $1 / 7$ th power law, ANFIS and local WSE is shown in Fig. 12. The ANFIS estimated WS values are in very close to the one obtained using local WSE while the ones obtained using $1 / 7$ th power law are much more deviated from the two.

\subsection{Scenario number three}

In this case, daily mean values of WS at all the measurement heights and for the entire data collection period were used. No data filters were applied in this particular case because the averaging process neutralized the abnormalities. A total of 550 daily average records were used for the purpose of extrapolating WS at higher altitudes. The daily mean wind speed predicted at $40 \mathrm{~m}$ using ANFIS are compared with the measured ones and were found to be in close agreement with MAPE of less than $1 \%$ and coefficient of determination $R^{2}$ value of $99.2 \%$. The WS values extrapolated using three different approaches are compared in Fig. 13.

\section{Conclusion}

This paper demonstrated the viability of ANFIS method for the estimation of wind speed at a higher heights based on wind speed knowledge at lower heights. Using wind speed at 10, 20, 30, and $40 \mathrm{~m}$, we were able to generate the wind profile up to $100 \mathrm{~m}$. The system was validated using wind speed at heights 10,20 , and $30 \mathrm{~m}$ to estimate the wind speed at height $40 \mathrm{~m}$. In this case the mean absolute percent error between the estimated value and the measured value is about 3\%. Moreover, the generated wind profile was compared to the $1 / 7$ th law and wind shear generated profiles. For future work the wind profile for several locations in Saudi Arabia will be generated and compared to wind shear and 1/7th law. Additionally, the system performance will be evaluated in locations where the wind profile is known up to height more than $150 \mathrm{~m}$.

\section{Acknowledgment}

The authors acknowledge the support of King Fahd University of Petroleum and Minerals.

\section{References}

[1] World Bank. Meeting the challenge for rural energy and development. The World Bank; 1999.<http://www.worldbank.org/html/fpd/energy/e4_files/ rural.pdf>.

[2] Painuly JP. Barriers to renewable energy penetration; a framework for analysis. Renew Energy 2001;24(1):73-89.

[3] Rehman S, El-Amin IM, Ahmad F, Shaahid SM, Al-Shehri AM, Bakhashwain JM. Wind power resource assessment for Rafha, Saudi Arabia. Renew Sustain Energy Rev 2007;11:937-50.

[4] Probst O, Cárdenas D. State of the art and trends in wind resource assessment. Energies 2010;3(6):1087-141.

[5] Marafia AH, Ashour HA. Economics of off-shore/on-shore wind energy systems in Qatar. Renew Energy 2003;28:1953-63.

[6] Ajayi OO. Assessment of utilization of wind energy resources in Nigeria. Energy Policy 2009;37(2):750-3.

[7] Ammari HD, Al-Maaitah A. Assessment of wind-generation potentiality in Jordan using the site effectiveness approach. Energy 2003;28:1579-92.

[8] Al-Nassar W, Alhajraf S, Al-Enizi A, Al-Awadhi L. Potential wind power generation in the State of Kuwait. Renew Energy 2005;30:2149-61.

[9] Ilinca A, McCarthy E, Chaumel JL, Rétiveau JL. Wind potential assessment of Quebec Province. Renew Energy 2003;28:1881-907.

[10] Dvorak MJ, Archer CL, Jacobson MZ. California offshore wind energy potential. Renew Energy 2010;35(6):1244-54

[11] Ahmad S, Hanitsch R. The potential of electricity generation on the east coast of Red Sea in Egypt. Renew Energy 2006;31:1597-615.

[12] Potts JR, Pierson SW, Mathisen PP, Hamel JR, Babau VC. Wind energy assessment of western and central Massachusetts. 2006. [AIAA-2001-0060]

[13] Brower M. Iowa Wind resource maps: a GIS approach. Iowa wind Energy Institute, Final Report; 1997. 
[14] Raichle BW, Carson WR. Wind resource assessment of the Southern Appalachian Ridges in the Southeastern United States. Renew Sustain Energy Rev 2009;13(5):1104-10.

[15] Muzathik AM, Wan Nik WB, Ibrahim MZ, Samo KB. Wind resource investigation of Terengganu in the West Malaysia. Wind Eng 2009;33(4):389-402.

[16] Ansari J, Madni IK, Bakhsh H. Saudi Arabian wind energy atlas. Riyadh, Saudi Arabia: KACST; 1986 . p. 1-27.

[17] Rehman S, Halawani TO. Statistical characteristics of wind in Saudi Arabia. Renew Energy 1994;4(8):49-956.

[18] Rehman S, Halawnai TO, Mohandes M. Wind power cost assessment at twenty locations in the kingdom of Saudi Arabia. Renew Energy 2004;28:573-83.

[19] Rehman S, Al-Abbadi NM. Wind shear coefficients and energy yield for Dhahran, Saudi Arabia. Renew Energy 2007;32:738-49.

[20] Al-Abbadi NM, Rehman S. Wind speed and wind power characteristics for Gassim, Saudi Arabia. Int J Green Energy 2009;6(2):201-17.

[21] Xydis G, Koroneos C, Loizidou M. Exergy analysis in a wind speed prognostic model as a wind farm sitting selection tool: a case study in Southern Greece. Appl Energ 2009;86(11):2411-20.

[22] Ucar A, Balo F. Investigation of wind characteristics and assessment of windgeneration potentiality in Uludag-Bursa, Turkey. Appl Energy 2009;86(3):333-9.

[23] Pinson P, Nielsen HA, Madsen H, Kariniotakis G. Skill forecasting from ensemble predictions of wind power. Appl Energy 2009;86(7-8):1326-34.
[24] Luickx PJ, Delarue ED, D'haeseleer WD. Considerations on the backup of wind power: operational backup. Appl Energy 2008;85(9):787-99.

[25] Kaldellis JK, Kavadias KA, Filios AE. A new computational algorithm for the calculation of maximum wind energy penetration in autonomous electrical generation systems. Appl Energy 2009;86(7-8):1011-23.

[26] Morales JM, Mínguez R, Conejo AJ. A methodology to generate statistically dependent wind speed scenarios. Appl Energy 2010;87(3):843-55.

[27] Fadare DA. The application of artificial neural networks to mapping of wind speed profile for energy application in Nigeria. Appl Energy 2010;87(3):934-42.

[28] Li G, Shi J. On comparing three artificial neural networks for wind speed forecasting. Appl Energy 2010;87:2313-20.

[29] Fakhreddine K, de Silva C. Soft computing and tools of intelligent systems design. UK: Pearson; 2004.

[30] Jang JSR. ANFIS: Adaptive-Network-Based Fuzzy Inference System. IEEE Trans Sys Man Cybern 1993;23(3):665-85.

[31] Ruano AE. Intelligent control systems using computational intelligence techniques. IET; 2005.

[32] Ying LC, Pan MC. Using adaptive network based fuzzy inference system to forecast regional electricity loads. Energy Convers Manage 2008;49(2):205-11.

[33] Potter C, Negnevitsky M. ANFIS application to competition on artificial time series (CATS), FUZZ-IEEE; 2004. [C.D.]. ISBN: 0-7803-8360-5. 